\title{
Improving Commitment to Organizations through the Development of Organizational Culture, Self-Efficacy, and Emotional Intelligence
}

\author{
Rudi Prihadi*, Thamrin Abdullah, Widodo sunaryo \\ PostgraduateProgram, Pakuan University, Bogor, Indonesia
}

*Corresponding Author: Rudi Prihadi, Postgraduate Program, Pakuan University, Bogor, Indonesia

\begin{abstract}
Commitment to the organization is influenced by various factors, including organizational culture, self-efficacy, and emotional intelligence. This study aims to determine the strength of the relationship between the independent variables with the dependent variable to increase commitment to the organization by increasing the indicators of related variables. Research on the sample of permanent foundation teachers totaling 402 people was selected by multistage sampling in 42 Private Vocational High Schools in the working area of Tangerang City with a significance level of research of 0.05. This study uses the correlational method and SITOREM Analysis. The conclusion obtained from the results of the study is that the greatest increase in commitment to the organization when increasing indicators of emotional intelligence variables. The other conclusion is that there is a significant relationship between organizational culture with a commitment to the organization with a correlation coefficient $r_{y l}=0.410(R=16.800 \%)$. Self-efficacy with commitment to the organization with a correlation coefficient $r_{y 2}=0.281(R=7.910 \%)$. Emotional intelligence with a commitment to the organization with a correlation coefficient $r_{y 3}=0.4815(R=23.180 \%)$. Organizational culture, self-efficacy, and emotional intelligence, together with a commitment to the organization with a correlation coefficient $r=0.896(R=80.600 \%)$. Besides, there are other factors of $19,400 \%$, which are also related to increasing commitment to the organization.
\end{abstract}

Keywords: Organizational culture, Self-efficacy, Emotional intelligence, Commitment, Organization.

\section{INTRODUCTION}

Commitment to organization is a commitment that is built naturally and fully supported by the awareness of each member of the organization to jointly manage and develop the organization towards a better and advanced. Commitment to the organization is the initial capital that must exist and its formation through agreements that are made together and carried out in full awareness following their respective fields and expertise that are managed through the division of work tasks.

Preliminary survey results conducted on 13-20 December 2018 at 9 private vocational schools in Tangerang City found problems of commitment to the teacher organization. It is found that: (a) There are $55 \%$ of teachers who have problems with indicators of mental bonding conditions to the organization (sense of belongingness) b) There are 53.3\% of teachers who have issues with the signs of the application of superior values in schools c) There are $58.3 \%$ of teachers who have problems with work suitability indicators in school organizations and who have issues with obligations d) There are $51.6 \%$ of teachers who have issues with future performance indicators. In devoting all their energy and thoughts to the interests of schools e) There are 51.6\% of teachers who have problems with signs of responsibility towards the Organization and in terms of wanting to leave from school.

Based on the results of a preliminary survey, it can be concluded that the commitment to the organization of teachers in private vocational schools in Tangerang City is still low, with an average commitment to the organization of $55.33 \%$ and need to be increased again. This is important because commitment to the organization can increase teacher loyalty to the organization, which is interpreted as the willingness of the teacher to perpetuate his relationship with the organization, if necessary, at the expense of his personal interests without expecting anything. The teacher's willingness to keep working in an organization is essential in supporting his commitment to the organization where he works. 
Improving Commitment to Organizations through the Development of Organizational Culture, SelfEfficacy, and Emotional Intelligence

Based on the above problem limitation, the research problem can be formulated as follows:

- Is there a relationship between organizational culture and commitment to the organization of private vocational high school teachers in Tangerang City?

- Is there a relationship between self-efficacy and commitment to private vocational teacher organizations in the city of Tangerang?

- Is there a relationship between emotional intelligence with a commitment to the organization of private vocational school teachers in Tangerang City?

- Is there a relationship between work ethic and commitment to the organization of private vocational high school teachers in Tangerang City?

\section{LITERATURE REVIEW}

\subsection{Commitment to the Organization}

According to Ambrose (2015), organizational commitment is about specific desires and beliefs, namely: a. A strong desire to remain a member of a particular organization or b. A desire to try hard following the wishes. Based on the description of the theories above, it can be concluded that commitment to the organization. The dimensions of commitment to the organization and its indicators, according to Schein(2010) include:

- Affective commitment, which is a commitment that shows a person's desire to continue working for the organization because he agrees with the goals and values of the organization and based on his desire to stay together with the organization with indicators: 1). willingness to be involved in working for a school, 2). acceptance of organizational goals.

- Continuance commitment, which is a commitment that shows a person's tendency to continue working in an organization because he does have to do it with indicators: organizational attention to the needs of its members, and the match between ability and work.

- Normative commitments, i.e., commitments that show someone to remain in the Organization due to social obligations that must be done with indicators: desire to continue together to become a member of the organization.

\subsection{Organizational Culture}

Organizational culture has a peculiarity in accordance with the accompanying environmental conditions, organizational culture is dynamic because it depends on the developing beliefs as stated by Al-Sharafi\&Rajiani (2013) that organizational culture is an assumption and shared beliefs about the world and the workplace including in the depth of space, time and human nature and the relationships between people. The mechanism that occurs there is two types of primary and secondary, namely the main mechanism consisting of things that must be intended by the leader, $b$. Ways to react to the crisis, c. Making a role model, d. Criteria for allocating awards, 5. Criteria for selection and dismissal. And thesecondary mechanisms: a. Management system design and procedures, b. The draft organizational structure, c. Facility design d. Stories, legends, and myths. Homogeneous statements, assumptions, and beliefs will be able to build good relationships.

\subsection{Self-Efficacy}

Achim (2014) defines self-efficacy is one's belief about the opportunity to successfully fulfill a specific task. Individuals with high self-efficacy will use their experiences, copy the success of others, support others, and their emotional maturity to strive for success. The self-efficacy factors are (a) primary experience, (b) behavior models (success from others). (c) persuasion from others, (d) physical / emotional status.

\subsection{Emotional Intelligence}

Fullan (2014) defines that emotional intelligence is a benchmark that refers to a variety of noncognitive skills, abilities, and competencies that affect one's ability to succeed in dealing with environmental demands and pressures. Emotional intelligence has five dimensions, namely: a. Selfawareness. Be aware of how you feel. b. Self-management. The ability to manage one's own emotions 
Improving Commitment to Organizations through the Development of Organizational Culture, SelfEfficacy, and Emotional Intelligence

and the stimuli that come. c. Self-motivation. The ability to survive in the face of a setback of failure. d. Empathy. The ability to handle other people's emotions. e. Social Skills. The ability to deal with other emotions. This is demonstrated by persuasion and expertise in building a group and leading a team.

Based on the description above, it should be suspected that there is a positive relationship between organizational culture, self-efficacy, and emotional intelligence, together with commitment to the Organization.

Based on the study of the theory and framework of thinking that has been described, a research hypothesis can be formulated as follows:

- There is a positive relationship between organizational culture and commitment to the Organization.

- There is a positive relationship between self-efficacy and commitment to the Organization.

- There is a positive relationship between emotional intelligence and commitment to the Organization.

- There is a positive relationship between organizational culture, self-efficacy, and emotional intelligence, together with commitment to the Organization.

\section{METHODS}

This study uses a combination of research methods between correlational research and SITOREM Analysis.Correlational research and SITOREM Analysis are combination research methods that combine correlational research methods whose results are strengthened using SITOREM Analysis. Through SITOREM Analysis, correlational research results are analyzed in more detail on indicators of research variables, so as to find indicators that need to be immediately corrected and maintained or developed.

The population is in the jurisdiction of Tangerang City, which consists of objects or subjects that have certain qualities and characteristics that are determined by researchers to be studied and then drawn conclusions temporarily. The study population was a vocational teacher in Tangerang City. Samples are part of the number and characteristics possessed by the population. Sampling in this study using multistage sampling techniques. This technique is done by taking a sample of $30 \%$ each from each district randomly to get a sample of a population of 402 permanent teachers of private vocational foundations that have the same characteristics in the duties and functions as a teacher which is then calculated using the sample size formula Taro Yamane. The number of samples used for the trial was 30 people out of 1,506 vocational teacher respondents in the city of Tangerang.

\section{RESULTS AND DISCUSSION}

\subsection{Relationship between Organizational Culture and Commitment to Organization of Private Vocational Teachers in the City of Tangerang}

The coefficient of determination between the teacher's organizational culture and commitment to the organization is $\mathrm{r}_{\mathrm{y} 1}{ }^{2}=0.0910$. This means that $9.10 \%$ commitment to the organization is the result of the workings of the variable organizational culture of the teacher, while $90.90 \%$ is contributed by other variables that have a relationship with increasing commitment to the organization. The findings obtained in this study indicate that organizational culture is a leadership style that has not been able to optimally motivate followers in an organization so that this leadership style can be more varied to create a sense of trust and increase commitment towards organizational organizational citizens simultaneously.

Quantitative research data above is reinforced by qualitative research data from observations, interviews and documentation studies can be concluded about the condition of organizational culture in each school that is observed to have a form of leadership that is relatively in accordance with the school environment, so that the qualitative organizational culture in the field have the same tendencies with organizational culture in quantitative terms. 
This is consistent with the theory of Lilians (2011), which defines leadership as a group of processes, emotional intelligence, fulfillment, certain behaviors, persuasion, authority, goal achievement, interaction, role differences, initiation of structure, and a combination of two or more than these things. The results of previous studies conducted before on the relationship between organizational culture stated the correlation coefficient on work of 0.880 , and this means the relationship between existing organizational culture with satisfaction with the whole work has a positive relationship and significant (Olcum,2015).

Based on the description above, it can be concluded that the better the organizational culture, the more commitment to the organization is also increasing. thus the findings of facts and data in the analysis of this study further support previous findings regarding the existence of a positive relationship between organizational culture and commitment to the organization.

\subsection{The Relationship between Self-Efficacy and Commitment to the Organization of Private Vocational Teachers in the City of Tangerang}

The coefficient of determination between the teacher's self-efficacy and commitment to the organization is $\mathrm{r}_{\mathrm{y1}}{ }^{2}=0.119$. This means that $11,900 \%$ of commitment to the organization is the result of the workings of the teacher's self-efficacy variable, while $88.100 \%$ is contributed by other variables that have a relationship with an increase in commitment to the organization. The findings obtained in this study indicate that self-efficacy is a conducive work environment felt by workers both directly and indirectly to carry out all organizational programs effectively and efficiently so that it impacts on increasing commitment to the organization.

The quantitative data above is strengthened by qualitative research data in the form of observational data, interviews and documentation studies which provide a detailed description and facts about the condition of self-efficacy in each school observed that has a distinctive pattern according to the situation in the field, so it appears that qualitative self-efficacy in the field have the same tendency with quantitative self-efficacy.

This is consistent with the theory of (Soyer,2010), stating that self-efficacy is a shared perception of members about what is happening in the organization in terms of management policies and practices. The factors are superior-subordinate relations, communication between members of the organization, members 'perceptions of organizational theories, members' perceptions of management practices (fairness). The results of previous research conducted by Werang (2014) about the relationship between emotional intelligence with a commitment to work, including self-efficacy and locus of control, states the correlation coefficient is 0.723 and 0.849 this means the relationship between emotional intelligence and work commitment has a positive and significant relationship.

Based on the description above, it can be concluded that the better and more conducive self-efficacy, the more commitment to the organization of the teacher is also increasing. thus the findings of facts and data in the analysis of this study further support previous findings regarding the existence of a positive relationship between self-efficacy and commitment to the organization.

\subsection{Relationship between Emotional Intelligence and Commitment to the Organization of Private Vocational Teachers in the City of Tangerang}

The coefficient of determination between the teacher's emotional intelligence and commitment to the organization is $r_{y 3}{ }^{2}=0.112$. This means that $11,200 \%$ of commitment to the organization is the result of the workings of the teacher's emotional intelligence variable, while $88.8 \%$ is contributed by other variables that have a relationship with increasing commitment to the organization. The findings obtained in this study indicate that emotional intelligence refers to the uniqueness of a person in various aspects, characteristics, and behavior that is displayed by a person when facing another person, an object or event to increase commitment to the organization.

The quantitative data above is reinforced by observations, interviews and documentation studies on qualitative research and it can be concluded that the condition of emotional intelligence in each school that is observed has a unique pattern according to its environmental conditions, so that qualitative emotional intelligence in the field has the same tendency with quantitative emotional intelligence. 
Improving Commitment to Organizations through the Development of Organizational Culture, SelfEfficacy, and Emotional Intelligence

This is consistent with the theory of Rangriz (2010), arguing that Emotional Intelligence refers to structures and tendencies in society that explain patterns of characteristic thinking, emotions, and behavior. Emotional intelligence has three factors, namely awareness, friendliness, neuroticism, openness to experience. This implies that Emotional intelligence is a characteristic pattern of thinking, emotion, and behavior that refers to the structure and tendencies of society.

The results of previous studies conducted by Aghdasi (2010) about the relationship between organizational regulations and commitment to organizational current salary pay and reward, benefits, promotion, positive $0.059,0.380,0.003$ the relationship between emotional intelligence and work commitment has a positive and significant relationship directly proportional to the highest level of education years as a board of certification for athletic trainers are 0.037, 0.218, 0.028 positive, so that in 5 research domains they are extroversion, agreeable, conscientiousness, neuroticism, openness, value positive agreeableness.

Based on the description above, it can be concluded that the better the emotional intelligence, the more the commitment to the organization of the teacher increases. Thus the findings of facts and data in the analysis of this study further support previous findings regarding the existence of a positive relationship between Emotional Intelligence with commitment to the organization.

\subsection{Relationship between Organizational Culture, Self-Efficacy, and Emotional Intelligence with Commitment to the Organization of Private Vocational Teachers in the City of Tangerang}

The coefficient of determination between organizational culture, self-efficacy, and emotional intelligence together with commitment to the organization is $\mathrm{r}_{\mathrm{y} 123}{ }^{2}=0.806$. this means that $80.6 \%$ of commitment to the organization is the result of the workings of organizational culture, self-efficacy, and emotional intelligence together, while $80,600 \%$ is contributed by other variables that have a relationship with an increased commitment to the organization.

Based on the description above, it can be concluded that the higher application of organizational culture, self-efficacy, and emotional intelligence will increase commitment to teacher organizations. Thus the findings of facts and data both quantitative and qualitative research results in the analysis of this study tend to further support previous findings regarding the relationship between organizational culture, self-efficacy, and emotional intelligence with a commitment to the organization. these results are in accordance with the calculation of the fifth hypothesis testing.

Based on the results of hypothesis testing, the achievement of increased commitment to the organization was obtained very significantly at $80,000 \%$ when organizational culture, self-efficacy, and emotional intelligence were applied proportionally while the remaining $20,000 \%$ in terms of increasing commitment to the organization is contributed by other variables that are related to the commitment variable towards the organization both, directly and indirectly, that was explored through Focus Group Discussion (FGD).

Other factors outside the research variables above are based on the results of the FGD, which show that among the factors outside of research related to increasing commitment to teacher organizations, there are four major factors that cause commitment to teacher organizations in Vocational High Schools in Tangerang City yet maximally improved. For this reason, immediate handling is needed so that the increase in commitment to the organization can be optimized and can provide excellent service. the contribution of other factors is $20,000 \%$, the mathematical contribution to each of these factors is only an estimate of the determination of the results of the correlation coefficient hypothesis testing that tests the relationship between organizational culture, self-efficacy and emotional intelligence together with a commitment to the organization of $80 \%$.

Based on the above figure, this study made an action plan to design programs that can be an alternative to improve matters related to improving the application of emotional intelligence indicators to permanent teachers of foundations and managers of private Vocational Schools in Tangerang in order to increase commitment to the organization in schools so that educational goals can be achieved more efficiently. 
Improving Commitment to Organizations through the Development of Organizational Culture, SelfEfficacy, and Emotional Intelligence

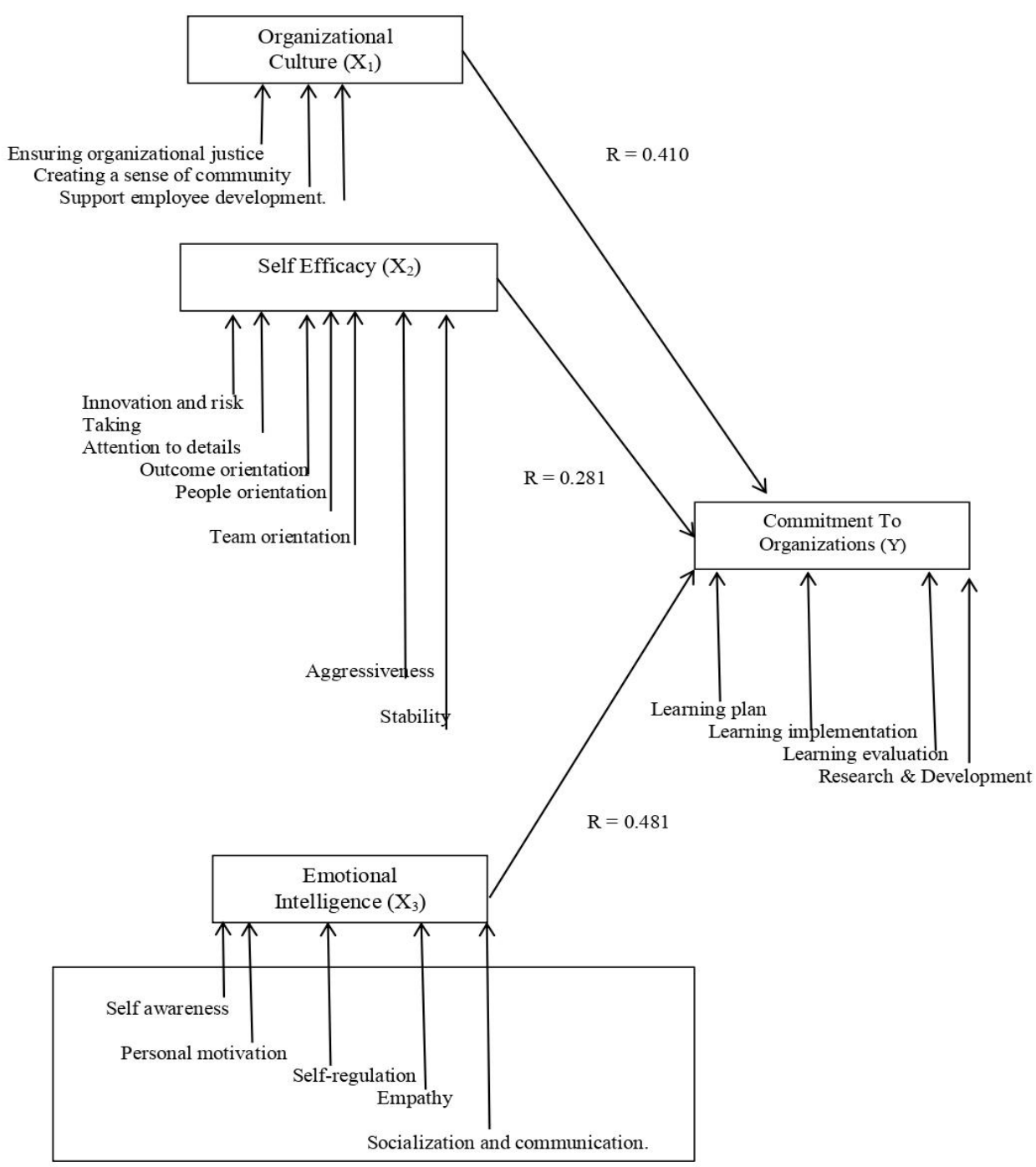

Figure1: Analysis SITOREM (Scientific Identification Theory for Operational Research in Education)

\subsubsection{Analysis of Contribution of Research Variables}

Based on the results of statistical calculations regarding the relationship of increasing commitment to organizations through the development of organizational culture, self-efficacy with emotional intelligence obtained the following data: 1 . The relationship between organizational culture and commitment to the organization's correlation coefficient $r_{\mathrm{y} 1}=0.409$; determination $\left(\mathrm{r}_{\mathrm{y} 1}\right)^{2}=0.168$; contribution $=16,800(\%)$, 2. The relationship between self-efficacy and commitment to the organization correlation coefficient $r_{\mathrm{y} 2}=0.2814$, determination $\left(\mathrm{r}_{\mathrm{y} 2}\right)^{2}=0.0791$, contribution $=7.9100$ (\%) 3.The relationship between emotional intelligence and commitment to the organization, the correlation coefficient $\mathrm{r}=\mathrm{y} 3=0.4815$, determination $(\mathrm{ry} 3)^{2}=0.2318$, contribution $=23.180(\%)$.

\subsubsection{Analysis of Research Indicators}

Activities of increasing the application of emotional intelligence variable indicators include the following things that have been sorted based on the results of research data analysis, namely: selfregulation $(3,336)$, empathy $(3,331)$, self-awareness $(3,324)$, personal motivation $(3,316)$, and socialization and communication $(3,268)$. Based on the data above, the priority application of selfregulation indicators is an indicator that must be formed through coaching and applied continuously so that it becomes an accustomed culture and becomes the character of the organization and its citizens.

\section{CONCLUSION}

Based on the results of data processing and analysis of research results show that the statistical calculation of hypothesis testing and discussion of research results and analysis of SITOREM 
Improving Commitment to Organizations through the Development of Organizational Culture, SelfEfficacy, and Emotional Intelligence

regarding increasing commitment to the organization through the development of organizational culture, self-efficacy and emotional intelligence which is an empirical study using correlational analysis and SITOREM analysis on Private Vocational Teachers in Tangerang City can be concluded that, there is a very significant positive relationship between organizational culture and commitment to the Organization with a correlation coefficient $\left(\mathrm{r}_{\mathrm{y} 1}\right)=0.409$ and a coefficient of determination $\left(\mathrm{r}^{2}\right)=$ 0.168.There is a very significant positive relationship between self-efficacy and commitment to the organization with a correlation coefficient $\left(\mathrm{r}_{\mathrm{y} 2}\right)=0.281$ and a coefficient of determination $\left(\mathrm{r}^{2}\right)=$ 0.079.There is a very significant positive relationship between emotional intelligence with a commitment to the Organization with a correlation coefficient $\left(\mathrm{r}_{\mathrm{y} 3}\right)=0.481$ and a coefficient of determination $\left(\mathrm{r}^{2}\right)=0.232$.There is a very significant positive relationship between organizational culture, self-efficacy, and emotional intelligence together with commitment to the organization with a correlation coefficient $\left(\mathrm{r}_{\mathrm{y} 123}\right)=0.898$ and a coefficient of determination $\left(\mathrm{r}_{\mathrm{y} 123}\right)=0.806$.

\section{REFERENCES}

[1] Aghdasi S, Kiamanesh AR, Ebrahim AN. Emotional intelligence and organizational commitment: Testing the mediatory role of occupational stress and job satisfaction. Procedia-Social and Behavioral Sciences. 2011 Jan 1;29:1965-76.

[2] Ambrose, Maureen L., Anke Arnaud, and Marshall Schminke. "Individual moral development and ethical climate: The influence of person-organization fit on job attitudes." Journal of Business Ethics 77, no. 3 (2008): 323-333.

[3] Al-Sharafi, Hamed, and Ismi Rajiani. "Leadership practices and talent turnover: Study on Yemeni organizations." Business and Management Research 2, no. 3 (2013): 60-67.

[4] Achim, Monica-Violeta, and N. S. Borlea. "Environmental performances-way to boost up financial performances of companies." Environmental Engineering and Management journal 13, no. 4 (2014): 991-1005.

[5] Fullan, Michael. Teacher development and educational change. Routledge, 2014.

[6] Hidayati, Tetra, and Rahmawati Rahmawati. "The effect on the job satisfaction organization, performance of employees commitment, and service performance." KINERJA 13, no. 1 (2016): 1-12.

[7] Lillian, G. O., P. Mathooko, and N. Sitati. "The Effects of Performance Appraisal System on Civil Servants Job Performance and Motivation in Kenya: A Case Study Of Ministry of State for Public Service." In Proceedings of 2011 Kabarak Univeristy 1 st Annual International Research Conference, p. 370. 2011.

[8] Olcum, Dincer, and Osman Titrek. "The effect of school administrators' decision-making styles on teacher job satisfaction." Procedia-Social and Behavioral Sciences 197 (2015): 1936-1946.

[9] Rangriz H, Mehrabi J. The relationship between emotional intelligence, organizational commitment, and employees' performance in Iran. International Journal of Business and Management. 2010 Aug; 5(8):50-6.

[10] Schein EH. Organizational culture and leadership. John Wiley \& Sons; 2010 Aug 16.

[11] Soyer, Fikret, Yusuf Can, and Kürşat Akbulut. "Examining the relationship between organizational commitment and job satisfaction levels of football coaches." Journal of Human Sciences 7, no. 2 (2010): 515-526.

[12] Werang, Basilius Redan, and Lukas Lena. "Relationship between Principal's Leadership, School Organizational Climate, and Teachers' Job Performance at State Senior High Schools in Merauke Regency-Papua-Indonesia." International Journal of Education and Research 2, no. 6 (2014): 635-640.

Citation: Rudi Prihadi, et.al. "Improving Commitment to Organizations through the Development of Organizational Culture, Self-Efficacy, and Emotional Intelligence" International Journal of Managerial Studies and Research (IJMSR), vol 7, no. 12, 2019, pp. 9-15. doi: http://dx.doi.org/10.20431/2349-0349.07 12002.

Copyright: (C) 2019 Authors. This is an open-access article distributed under the terms of the Creative Commons Attribution License, which permits unrestricted use, distribution, and reproduction in any medium, provided the original author and source are credited. 